\title{
Recommendation System for Selection of Majors and Apprenticeship on Vocational and Training Education Based on Competency to Produce Demand Driven Graduates
}

\author{
Agus Aan Jiwa Permana ${ }^{1}$, Luh Joni Erawati Dewi ${ }^{2}$, Komang Setemen ${ }^{3}$ \\ Informatics Management \\ Universitas Pendidikan Ganesha \\ Singaraja, Indonesia \\ 19agus.aan@undiksha.ac.id, 2joni.erawati@undiksha.ac.id, ${ }^{3}$ k.setemen@undiksha.ac.id
}

\begin{abstract}
This research aims to produce demand driven human resources through vocational education and training. In the process of realizing it, it is necessary to innovate in several sectors, such as the selection of appropriate majors and apprenticeship process in accordance with the competence of students in the middle to college level. The method applied in this research is to do the selection process for new students by giving recommendation of the department which is in accordance with the competence of the students by taking the majors test. Then the students will take part in the apprenticeship, will take the test and with some component of the value of the course or course, the value of report cards, and the GPA will be processed and produce recommendation of apprenticeship location in accordance with the student's competence. The impact of this research is students who are in the appropriate majors, will affect the comfort in the learning process so as to maximize student potential. The apprenticeship location recommendation aims to provide work comfort, work motivation, good career expectations for students who attend apprenticeships in the industrial world. So the graduates produced by vocational education is demand driven.
\end{abstract}

Keywords - Vocational Education and Training, Majors Recommendations, Apprenticeship Recommendations, Student Competencies, Demand Driven

\section{INTRODUCTION}

Education is an important impact to the nation, so education becomes a priority in the Nawacita (Nine Goals) of President Ir. Joko Widodo. The President is very supportive of the community in the field of education [1], At least by following the nine-year education program. By following the nine-year education, it is expected to increase the knowledge and skills to compete in the era of globalization and free market. In acquiring skills, it must be done through vocational education. Vocational education and training is available from high school to college. But statistics of 2016 shows graduates of Vocational Middle School has an unemployment rate of $9.84 \%$. This value is higher than unemployed high school graduates $6.95 \%$, junior $5.76 \%$, and elementary school $3.44 \%$ [2]. This situation is certainly not good for a nation that competes in the ASEAN economic community. The number of highly educated workers who work as much as 14.57 million $(12.24 \%)$ of 118.41 million people working, and as many as $787,000(11.19 \%)$ of 7.03 million unemployed people [3]. It is also a big problem for college in Indonesia, where many of their graduates are unemployed.

Many things affect the competence and career of graduates in the world of work. The first step to be considered is the process of determining the majors. At vocational school the process of direct admission continues to the process of majors. The early majors confuse the students because many junior students choose majors based on interests, not on the basis of competence. The determination of the majors made so far has many weaknesses, only based on the wishes of students without looking at the profile of academic value [4]. Research [5] said that by choosing the right academic discipline and strong motivation affect the achievement of a relevant career. Improper misappropriation may be detrimental to students and their careers in the future. Because by choosing the right majors are expected to maximize the potential, talent or individual talents, so as to maximize its academic value [4]. The selection of vocational majors in general has increased, which is a significant factor for people entering the workforce and based on statistical data of the number who took vocational programs based on gender in 1992-1993 male: $3.2 \%$ and Female: $1.3 \%$ whereas in $1999-2000$ with male: $3.3 \%$ and Female: 1.6 [6].

One of the factors of student failure in the academic field is because the chosen majors are not in accordance with the interests and abilities of the students. Tendency Prospective students to register for following trends or coercion of parents who have a negative impact on student achievement [7] Prospective new students require election or course selection appropriate to their interests and abilities, not just on the recommendation of friends or family who may have different interests and talents [7]. The purpose of this research is to help students in choosing majors not in accordance with the wishes, but in accordance with its competence with the help of a tool.

In the process of improving student skills, vocational education holds an apprenticeship program. The 
apprenticeship program is one of the solutions to provide students with experience to work within a certain time in the industry. It is necessary to develop modern apprenticeship concept with the form of relationship of four components namely enterprises, goverment, industry and society which have different rules and connected in an environment that can provide important guarantee for vocational education and training [8]. Knowledge gained while learning is applied in the industry, it provides students with experience for their career success. Industrial world has opened opportunities for students who do apprenticeships, so the apprenticeship experience can add insight and knowledge of students [9]. But sometimes apprenticeship do not run as expected, students do apprenticeships that are not in accordance with the field of competence [9]. This situation has an impact on the decreasing of students' motivation during the apprenticeship, so that the apprenticeship is not working maximally. Research has been done which states that apprenticeship and work motivation is very significant with the readiness of students' work [9].

The apprenticeship program is undertaken in an effort to improve the competence, experience, as well as train students soft skills both in school and college. The need for a structured subject-dependent curriculum to guide teachers and learners is obvious, and fortunately there is such a curriculum [10]. In addition to gaining knowledge in schools and college, students are expected to have knowledge in meeting the demands of the working world [11]. The still high number of unemployment is caused by several factors such as lack of employment, low economic ability, and unsuitable competence of graduates with the needs of the industrial world. In overcoming the skill gaps from job seekers it is related to the issue of quality and relevance of educational outcomes.

Vocational education world, faced with the problem of how to produce graduates with qualifications relevant to the needs of the workplace so that the rate of absorption of graduates in the workplace increased [12]. A highly motivated student is reflected in the experience at the time of apprenticeship and provides experiences directly in the field but aims to make students better prepared for entry into the real world of work [13]. With work motivation and apprenticeship experience, in the information age of schools and campuses need to establish cooperation with the stakeholders so as to facilitate students in finding work information. It needs an efficient, interactive collaborative technology approach in terms of apprenticeships, training, and learning [14]. The apprenticeship program is not just for training in getting vocational skills but is a process for lifelong learning for life [15].

The purpose of this research is to help give recommendations of students who will follow the apprenticeship to choose the apprenticeship place in accordance with their competence with the help of tools so as to increase the motivation of work in the industrial world that produces competent, competitive graduates and become a reliable workforce, ready to compete in National and International levels. Competency has three main components such as knowledge, skills, and attitudes. These three things can be the basis for measuring the competence of students who will follow the apprenticeship. So that students who follow the apprenticeship is not based on interest only but also based on ability. In this research the innovation used is a hybrid system. Hybrid system that is meant here is the integration of Information Systems Selection of Departments for the selection process of majors when admissions and Artificial Intelligence in the process of recommendation of determining the location of internship for students who will follow the internship. Core of Information System is adopted from Test of Inventory Personal Survey which produces recommendation of majors according to student's interest and ability which is divided into six elements such as RIASEC.

After students enter and follow the learning process, it will increasingly improve their skills, increasing skills will improve student competence. In entering the final semester, students are required to follow industry practice (apprenticeship). In the process of determining the location of the internship, students experience confusion. By developing an AI-based apprenticeship recommendation system, it can be a solution to provide internships based on student competency. Why should I use AI? Of course this time, it is the Big Data trend so that student apprentices' previous data can be filtered and used in providing apprenticeship recommendations. Variables used in this AI system is the value of the course, GPA, and the latest test results using the Test Personal Inventory Survey so that the expected results are more valid because it has cognitive, affective, and psychomotor elements.

\section{METHODOLOGY}

\section{1 Participant}

The respondents involved in the research came from two different levels. The first level is the new student who will follow the selection to get the majors. Students take the test to choose the majors they want based on their competencies. In the early stages, participants fill out their personal profile and the department they want. Then the second respondent is the student who will do apprenticeship to the company and office. The respondents involved in this test are three diploma students who are in the final five semesters. Students fill out forms with identities and items used for the process. This research involves schools and vocational college to ensure that input data coming from the vocational school level has been selected, and students who will follow the apprenticeship to produce graduates with good skills and readiness to work.

\section{2 Data Collection}

Data collection process is done by several stages. At the stage of majors, data required is the identity of students and departments desired. Then the students will follow a kind of placement test that was adopted from Inventory Personal Survey (IPS) developed by Holland. IPS has six components: realistic, investigative, artistic, social, enterprising, and conventional (RIASEC). These six components are contained in four indicators, among others [16]:

1. Interest and involvement in an activity.

2. Self-perception of the ability to do a field / expertise.

3. Interest and interests in certain occupations or occupations. 
4. Self-assessment to be able to work on certain areas of expertise.

Assessment in IPS for indicators 1-3 using Guttman scale model is firmly "Yes" or "No" and While the 4th indicator uses differential semantic scale model (SD) using score with range (1-7). The test was done within a pre-determine time duration of 10-15 minutes. The test results will show the first, second, and third largest values of the six components (RIASEC) that will determine the recommendation result of the system of majors and the results can be discussed further with the counseling experts at the school / college.

In the apprenticeship process, the data needed to measure competence are knowledge, psychomotor, and affective (KPA) from the students who will be apprentices. The knowledge value can use the GPA or the last report card value. Psychomotor value is the value of subjects / subjects that are very influential on the profile of graduate school / college. Then the last is the affective value that can use the value of personality related to the competence of RIASEC in IPS. The KPA scores will be processed and classified by artificial intelligence (AI) that can result in recommendation of an apprenticeship location in accordance with student competence.

\section{3 Data Analysis}

Based on the data already collected in the field, next will be held analysis related to missing value which will cause the process of classification error during training data. When IPS tests are conducted, the results of the tests obtained by the students are recorded and the results are immediately discussed with the counselor. If there is a deviation on the results during the IPS test, it will be retested to get the results of the appropriate test the maximum test is done up to three times. Then the apprenticeship system for KPA data has a range of different values so that when the training process, normalization process data must be done. This process can help speed up the process of training data, so that data can be recognized well by the system. If the training process runs smoothly, then it will produce good results during the testing process.

\section{4 Architecture of System Majors}

The major process uses six components of the IPS which are then summed in total per component. The results of the total number of the six components are then sorted by ascending (largest to small value) which is the 1st (primary), 2nd largest (secondary), and 3rd largest (tertiary). Indicator 14 has some questions that students must answer. The four indicators containing the RIASEC elements each have scores obtained from the "Yes" answer on each question that must be answered. The three largest values of the four indicators containing the RIASEC score will be taken and then sorted into the primary, secondary, and tertiary scores. Based on primary, secondary, and tertiary values, it will be used to determine which majors are suitable for students. Furthermore, students will be given a choice of suitable majors based on the test results, and then the committee can announce the test results whether the desired student majors are appropriate or not. The architecture of the majors can be seen in Figure 1.

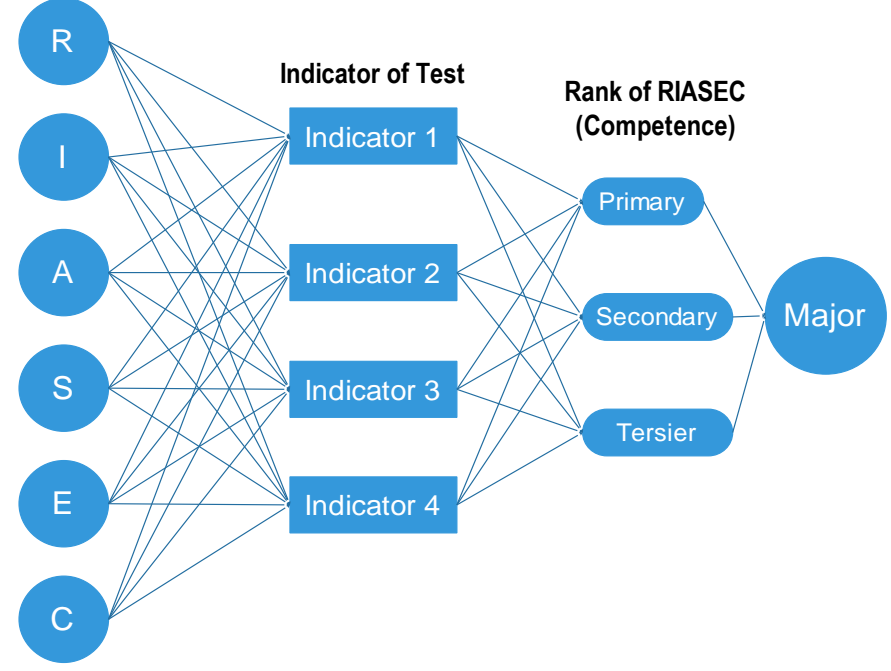

Fig. 1. Architecture of System Majors

\section{5 Architecture of Apprenticeship System}

In facilitating the understanding of the processes occurring from the apprenticeship system, it can be illustrated as Figure 2. Based on theory, someone who is said to be competent must master the three components such as knowledge, psychomotor, and affective. These three components must be absolute and measurable to be used in the system. The knowledge of the school students in following all the lessons is seen from the last report result, while the collage of this knowledge can be seen from the last GPA score. Then to measure psychomotor actually already appears when students follow the lessons in the classroom or in the laboratory.

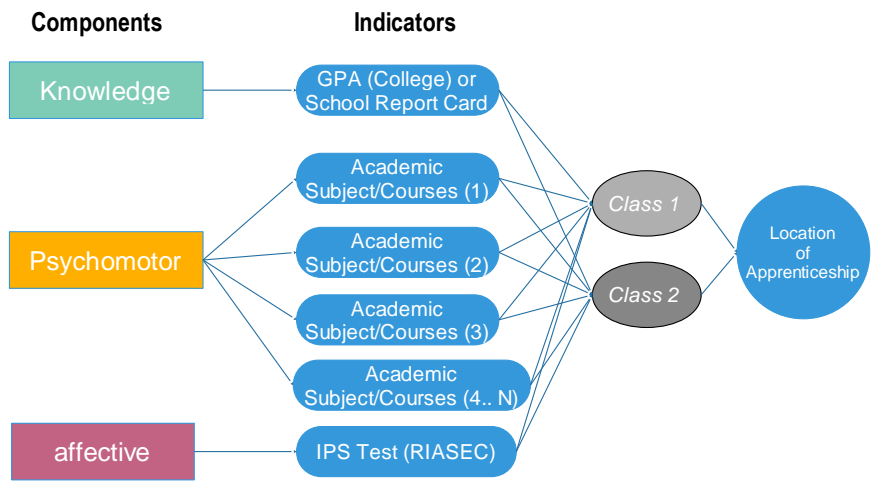

Fig. 2. Architecture of Apprenticeship System

If students follow the lessons seriously, the results obtained will certainly not disappoint. However, it should be noted that the value used here is derived from subjects or courses that play a dominant role against the graduate profile 
of their respective vocational majors. Suppose the department has a graduate profile as a programmer, certainly courses that can be represented are algorithms and programming because these subjects much influence the potential and skills of students in the world of programming. If the graduate profile in multimedia, of course the value that can be represented are multimedia or multimedia introduction.

Then in the process of determining affective score, it is a little bit difficult if it is changed into a score. But with IPS, a person's competence can be measured based on his personality. This test has been widely adopted in the world to determine career success, position placement, and to find a suitable working environment. All indicators used like Figure 2 are processed and then carried out the training process. The training process will produce two outputs, which are binary numbers divided into classes 1 and class 2 . These two classes will represent the existing apprentices in which category.

\section{RESULT}

This research has resulted in an alternative solution to provide students with choices in vocational education so that schools and colleges can make effective majors from the initial process of admission. By accepting students who take the appropriate majors, it will provide comfort in the learning process. Through the process of learning and training in skills will improve student competence. After entering the final semester, with the knowledge and skills that have been learned, then the student is ready to enter the world of work through an apprenticeship.

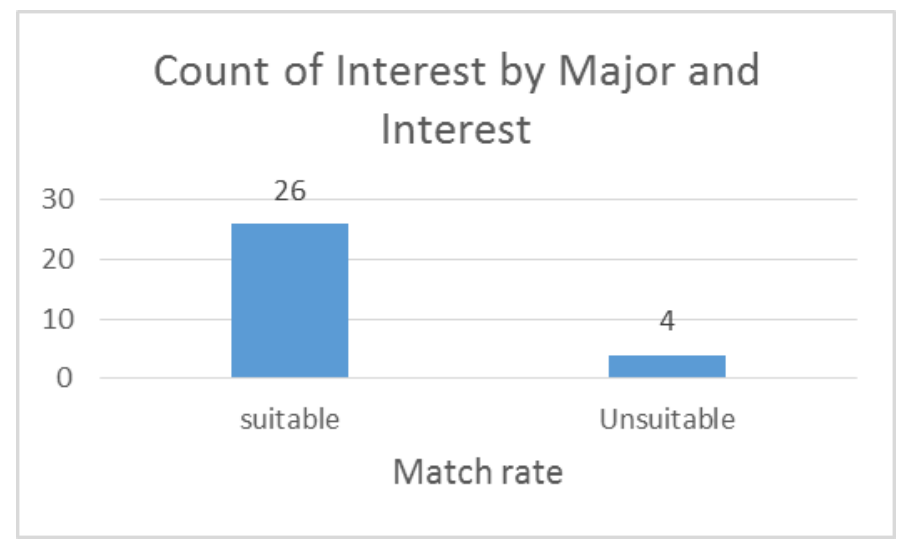

Fig. 3. Match Rate between Majors and Interests

Recommendations location apprenticeship aim to provide working comfort, motivation for students in apprenticeship. The system only helps make recommendations in accordance with the location of the apprenticeship student competence according to the apprenticeship that has been done before. The success of apprenticeship in the industrial world remains entirely determined by the students themselves, because there are many factors that influence the success in apprenticeship programs.

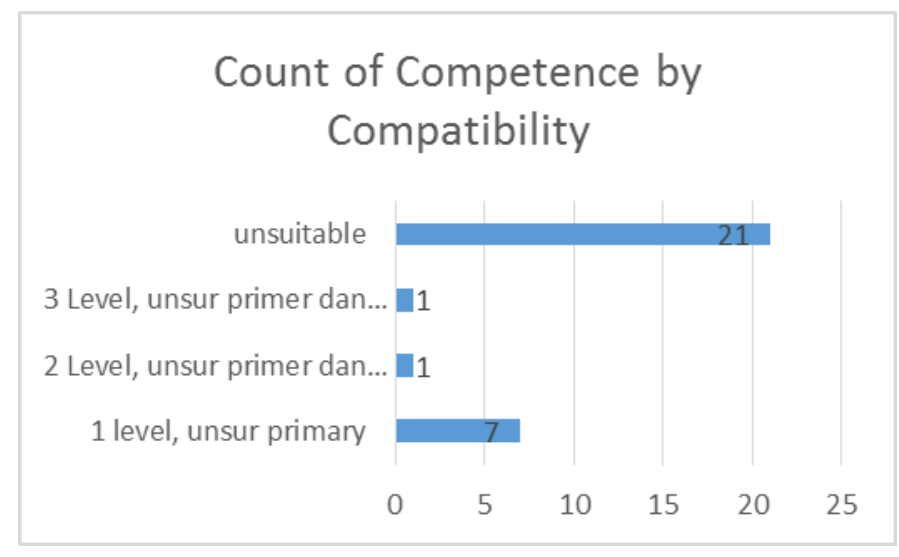

Fig. 4. Match Rate between the Majors with Competence

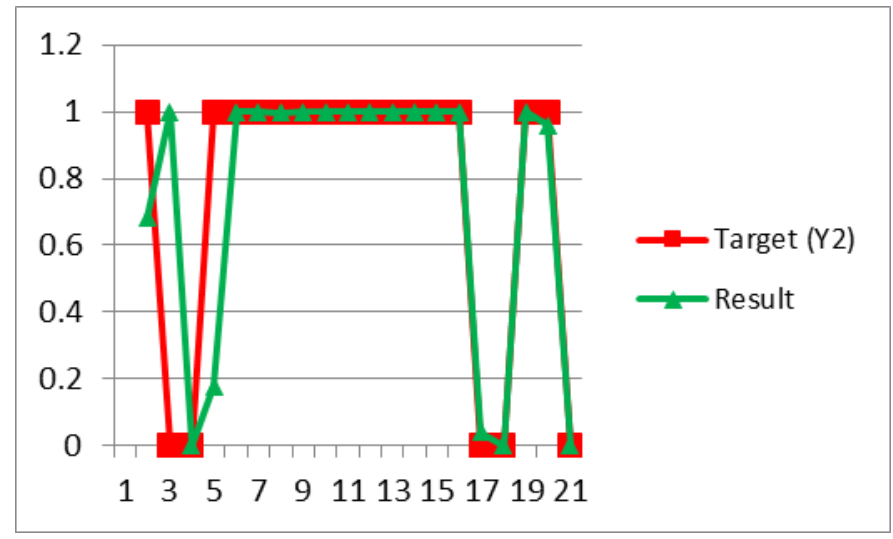

(a)

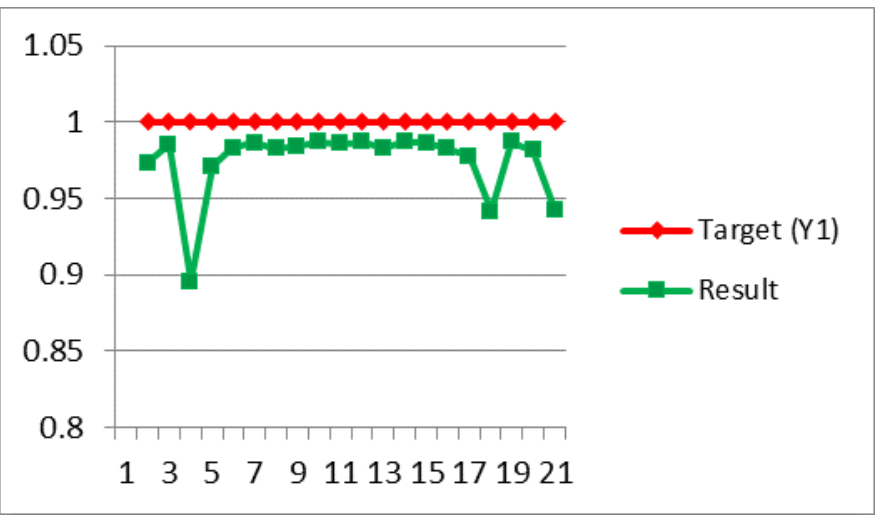

(b)

Fig. 5. Difference of Result with Target Class1 (Y1) and Class1 (Y2) Based on Fig. 2

The Collecting of preliminary data on the selection of majors is done by spreading the questionnaire to 30 students related to the chosen majors and the majors that students are interested in SMK N 3 Singaraja. This result can be used as an illustration in the development of Department of Information Election Information System. There is a graph of interest conformity with the student's chosen majors such as Figure 3. 
Based on Figure 3, it shows the degree of conformity between the interests of students with the chosen majors. Information Systems being developed serve as filter between the interests of students' abilities to the chosen majors, so students do not choose the wrong majors. It is in accordance to the data between the majors selected, many are inconsistent with student competence in the graphs such as Figure 4, which indicates that many students are taking a major that is incompatible with their competence.

Then in the case of apprentices, students are faced with the choice of apprentice location appropriately. With the data training of 88 data that have been normalized, it will produce the appropriate weight to provide internship recommendations in accordance with student competence. In the training process, the required data is $75 \%$ of the overall data. After the training process, to test the ability of the system, we can use the data testing of $25 \%$ of the overall data. After undergoing the training and testing process, the system is ready to be tested with new data that has never been recognized. The system can provide the best results, can be affected by some things like missing value, data variation, and amount of data used. The result of the data testing process is that there is a gap between real results and targets such as Figure 5a and 5b. These figures explain that the difference between real and targeted data is not too far away, so the system is ready for testing with new data.

\section{DISCUSSION}

The major recommendation process helps schools in directing new students who will choose majors. Mistakes in choosing a course will result in very bad because students cannot maximally follow the lesson. It also affects the career of the students while working after graduation later. Based on this, the recommendation system becomes a solution to lead the students to the right direction in accordance with the wishes and abilities of students. In research conducted [7] Using the Naïve Bayes method to assist the classification process in determining recommendations for students and research [4] Using the C4.5 and K-Means methods, this is very different from the ongoing research because it uses a more personal approach method that is IPS by giving questions to the students related to their habits, the things they like. So that when answering, they do not know that the actual test results that come out show their potential to follow the majors and develop the skills maximally.

Constraints in this study were the students are not serious in completing the questionnaire so that the test system can be made online, with pretest. Then after student test scores are obtained and not worth, it will be given up to twice the tolerance test. If the results do not match up to then, the last alternative is a return to interest selected.

In addition to the recommendation process majors, this research also provides apprenticeship locations in accordance with the recommendation of student competence. By recommending appropriate apprenticeship location, students will maximally develop their own skills in the industrialized world. There is a recommendation system developed with adaptive methods of using social media to develop individual skills [17]. Research on the use of online forums to develop student skills in apprenticeships [18], then to support the competency of the apprentice participants is done by developing a Portal [10]. Some research that had been done was focusing on the supervision, learning, and skills development of students during the apprenticeship. Meanwhile, the current research is focusing on choosing the right apprenticeship location to develop students potential and skills while apprenticing.

\section{CONCLUSION}

The recommendation system developed for election majors and apprenticeship selection has a significant effect on the selection process of students to direct to the appropriate apprenticeships based on competence. In relevance that competent students will have excellent career opportunities, good job readiness, and good career expectations after graduated. This system needs to get feedback from the reader to improve their performance during the process of issuing a recommendation and solution. If the results on the first stage tests do not match the competence of the interest the student wants. System can choose three different interests when applying for majors. Test results at the beginning will be matched with the student's first interest, if is not suitable, it will be matched with second interest and so on. The results of tests that match the student's interest can be seen in Figure 6.

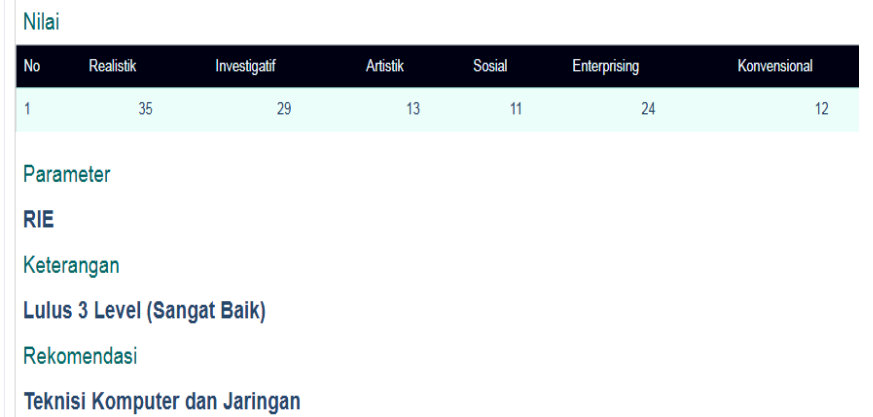

Fig.6. Test Results

By using the tools, it is shown to be having a significant impact on vocational education because it is the foundation to train and improve the skills of human resources that are the most important asset in developing a nation. In case apprentice, IPS method, GPA, and courses scores are used for recommendation process in major that is supported by AI such as Artificial Neural Network for classification process. This system has been able to give recommendation of location of apprentice. The output of the classification process has 2 classes in binary form namely class 1 (Y1) and class 2 (Y2). Test results during the data testing process, the outputs of the system with the desired target, have a range close to the target. According to Figure 7, based on $80 \%$ of the training data that are already assigned to the internship location 
recommendation system, when test with 20 data, $90 \%$ of the data, can be well recognized and $10 \%$ of the data have a range of value that is somewhat far away with the desired output so that the system can be feasible for the apprentice location classification process. Both recommendation systems strongly support government programs that want to produce demand driven graduates and need to be integrated further in vocational school.

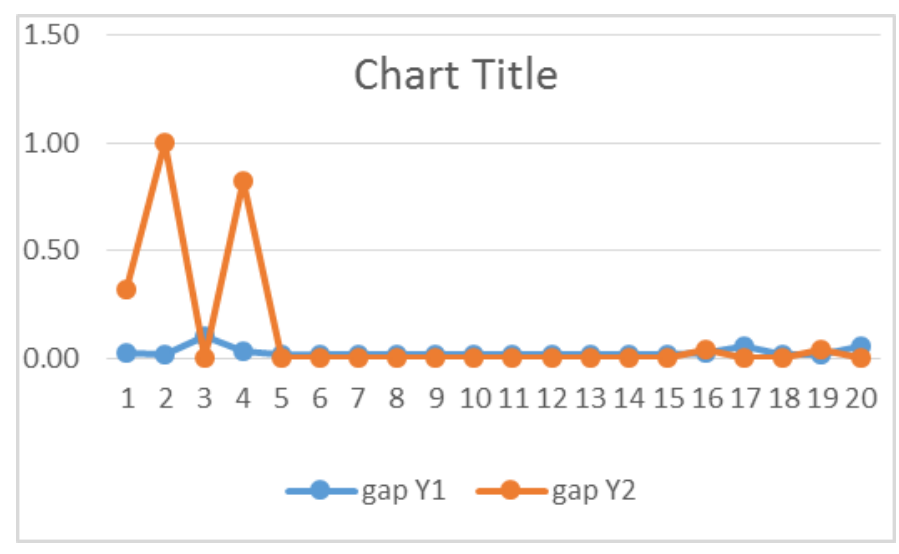

Fig.7. Gap from Testing Data

\section{ACKNOWLEDGMENT}

The results resulted in the article are received with Grant Institution (DIPA) 2017 "Development Test Inventory Personal Survey (TIPES) Online as a Selection Recommendations of Major on Vocations School ".

\section{REFERENCES}

[1] Kompas, “ Nawa Cita, Jokowi-JK Priority Agenda,” pp. 1-5, 2014. (in indonesian)

[2] Humas, "The majority of unemployed vocational graduates, President Jokowi Ask Vocational Education System Reconstructed," pp. 20162017, 2016. (in indonesian)

[3] Nusakini, "Minister of Manpower: Higher Education Must Prepare Demand-Driven Graduates," pp. 4-7, 2017. (in indonesian)

[4] S. N. Nugroho, Yusuf S., Haryati, "Classification and Clustering Majors of Senior High School Students 3 Boyolali,” vol. I, no. 1, pp. 3-8, 2015. (in indonesian)

[5] N. Maliszewski and A. Werner-maliszewska, "The impact of explicit and implicit power motivation on educational choices," vol. 45, no. 3, pp. 275-285, 2014.

[6] C. E. Freeman, T. D. Snyder, and B. Connolly, "Education Policy Analysis Archives," 2005.

[7] D. P. Kusumaningrum and N. A. Setiyanto, "Recommendation System for Major University Determination Based on Student, $s$ Profile and Interest," vol. 2, no. 1, pp. 21-28, 2017.
[8] A. Diao, "Vocational Education Modern Apprenticeship Development Strategy Researh," vol. 5210, 2015.

[9] I. M. Sirsa, N. Dantes, I. G. Ketut, and A. Sunu, "Contribution Of Career Expectation, Motivation Of Working, And Industrial Work Experience On Student Preparation Of Class Xii Vocational Secondary School 2 Seririt,” e-Journal Progr. Pascasarj. Univ. Pendidik. Ganesha Progr. Stud. Adm. Pendidik., vol. 5, 2014. (in indonesian)

[10] Y. Atif, E. A. Khousa, S. S. Mathew, K. Al Awar, and N. Al Sayari, “A Portal Support to Cognitive Apprenticeship,” pp. 449-453, 2014.

[11]A. A. J. Permana and W. Prijodiprodjo, "Feasibility Evaluation System of Student Apprenticeship Using Elman Recurrent Neural Network," IJCCS (Indonesian J. Comput. Cybern. Syst., vol. 8, no. 1, pp. 37-48, 2014. (in indonesian)

[12]I. M. Suarta, "Relation Of Learning System, Learning Environment, Self Concept And Development," J. Penelit. dan Eval. Pendidik., pp. 24-41, 2010. (in indonesian)

[13] Y. Kusnaeni and S. Martono, "Influence Perception Of Apprenticeship Information Entering The World Of Work And Motivation World Of Work On Student Employment Readiness Vocational High School," vol. 5 , no. 1, pp. 16-29, 2016. (in indonesian)

$[14] \mathrm{K}$. W. Jones et al., "Collaborative Technologies: Cognitive Apprenticeship, Training, and Education," 2008.

[15]C. R and M. Yasin, "Cultivating Learning : A Grounded Theory Of Skills Acquisition For Vocation In Modern Apprenticeships," Procedia - Soc. Behav. Sci., vol. 174, pp. 275-282, 2015.

[16]K. Suratana, Compliance Relationship Between Personality Type and Environment Model by Maturity Directions Career options (Studies in Class XII in SMK N 1 Padang). Padang: Guidance and Counseling Study Program, Postgraduate Program State University of Padang, (Thesis : Unpublish), 2009. (in indonesian)

[17]C. Di Valentin, A. Emrich, J. Lahann, D. Werth, and P. Loos, “Adaptive Social Media Skills Trainer for Vocational Education and Training: Concept and Implementation of a Recommender System," 2015.

[18] M. F. Ali, L. Tahir, M. Nihra, H. Said, and N. M. Tahir, "Integrating Cognitive Apprenticeship Strategy with the use of Online Forum in Developing Product Assignments," no. 2010, 2015. 